\title{
Entamoeba polecki
}

National Cancer Institute

\section{Source}

National Cancer Institute. Entamoeba polecki. NCI Thesaurus. Code C122298.

A species of commensal parasite in the class Archamoebae. E. polecki is considered nonpathogenic. This species is primarily a parasite of pigs and monkeys, and human infection is more prevalent in areas where the people have animal contact. 